\title{
Novel long non-coding RNA RP11-119F7.4 as a potential biomarker for the development and progression of gastric cancer
}

\author{
JINGXU SUN", YONGXI SONG* ${ }^{*}$ XIAOWAN CHEN, JUNHUA ZHAO, PENG GAO, \\ XUANZHANG HUANG, HUIMIAN XU and ZHENNING WANG
}

\author{
Department of Surgical Oncology and General Surgery, First Hospital of China Medical University, \\ Shenyang, Liaoning 110001, P.R. China
}

Received August 22, 2014; Accepted April 20, 2015

DOI: $10.3892 / \mathrm{ol} .2015 .3186$

\begin{abstract}
Long non-coding RNAs (lncRNAs) have been reported to be involved in gene dysregulation in numerous different types of cancer, and have subsequently emerged as a major series of regulatory molecules that participate in a broad range of biological and pathological processes. However, the correlation between the expression levels of lncRNAs and their clinical significance in gastric cancer remains unclear. The aim of the present study was to investigate the potential correlation between lncRNA RP11-119F7.4 expression and clinicopathological characteristics in gastric cancer, and to identify whether it can serve as a potential diagnostic biomarker of the disease. Total RNA was extracted from the tissues of 96 patients with gastric cancer, in addition to matched non-tumor adjacent tissues (NATs). Following reverse transcription, 1ncRNA RP11-119F7.4 expression levels were determined by quantitative polymerase chain reaction and the association with patient clinicopathological characteristics was further analyzed. A receiver operating characteristic (ROC) curve was constructed to determine the diagnostic value of RP11-119F7.4. The results demonstrated that RP11-119F7.4 expression was significantly downregulated in the gastric cancer tissues compared with the matched NATs $(\mathrm{P}<0.001)$ and was significantly associated with the
\end{abstract}

Correspondence to: Professor Zhenning Wang, Department of Surgical Oncology and General Surgery, First Hospital of China Medical University, 155 North Nanjing Street, Shenyang, Liaoning 110001, P.R. China

E-mail: josieon826@sina.cn

*Contributed equally

Abbreviations: lncRNA, long non-coding RNA; NATs, non-tumor adjacent tissues; OS, overall survival; ROC, receiver operating characteristic; miRNA, microRNA; TNM, tumor-node-metastasis; GAPDH, glyceraldehyde 3-phosphate dehydrogenase; DFS, disease-free survival; ceRNA, competing endogenous RNA

Key words: gastric cancer, long non-coding RNA, diagnosis, biomarker macroscopic type $(\mathrm{P}=0.041)$ and Lauren grade $(\mathrm{P}=0.020)$. The area under the ROC curve was $0.637(\mathrm{P}<0.001)$. However, no statistically significant differences were observed between RP11-119F7.4 expression and patient survival. The results of the present study indicate that IncRNA RP11-119F7.4 may be involved in carcinogenesis and may prove useful as a biomarker for diagnosis and prognostic significance in patients with gastric cancer.

\section{Introduction}

Gastric cancer is the fourth most common malignancy and the second leading cause of cancer-associated mortality worldwide, with an overall survival (OS) rate of 20-25\% reported in the majority of countries $(1,2)$. Despite continued improvements in medical technologies and treatment strategies, major obstacles to the treatment of gastric cancer remain, including delayed diagnosis, recurrence, metastasis and a poor prognosis $(3,4)$. Therefore, the elucidation of novel molecular mechanisms and the identification of biomarkers for the development and progression of gastric cancer should be investigated.

In the human genome, protein-coding genes account for $\sim 2 \%$ of the total genome sequence. However, $\geq 90 \%$ of gene sequences are primarily transcribed into non-coding RNAs (ncRNAs) (5). Over the past several years, short ncRNAs, such as microRNAs (miRNAs), have been comprehensively studied. Long ncRNAs (lncRNAs) are generally considered to be mRNA-like transcripts longer than 200 nucleotides (nt), but they do not function as templates for protein synthesis (6). An increasing number of studies have focused on IncRNAs, which have been demonstrated to contribute to the onset and progression of numerous diseases (7). Functional analyses have indicated that lncRNAs are involved in the regulation of a large number of biological processes, including cancer development and progression $(8,9)$. Expression of the IncRNA, HOTAIR, has been correlated with tumor metastasis and poor prognosis in hepatocellular (10), pancreatic (11), breast (12) and colorectal cancer (13), and gastrointestinal stromal tumors (14). Furthermore, aberrant expression of certain lncRNAs, including ANRIL, MALAT1, H19, GAS5 and MEG3, have been reported in a number of different types of cancer (15-19). However, the 
roles of lncRNAs in gastric cancer and their association with clinicopathological characteristics in this disease remain largely unknown and therefore require further study.

The RP11-119F7.4 gene is located on chromosome 10 (70451421-70452698), and codes for an antisense lncRNA with a length of 349 nts. However, whether there is an association between this specific lncRNA and cancer is unclear. Therefore, the primary aim of the current study was to investigate the expression pattern of 1ncRNA RP11-119F7.4 in gastric cancer tissues and matched non-tumor adjacent tissues (NATs) as a possible biomarker; and to evaluate the correlation between its expression level and clinicopathological characteristics of patients with gastric cancer.

\section{Materials and methods}

Tissue samples. Human gastric cancer tissue samples and pair-matched NATs were obtained from 96 patients who underwent radical resection of gastric cancer between November 2007 and May 2009 at the First Hospital of China Medical University (Shenyang, Liaoning, China). Informed consent was obtained from all patients and the study protocol was approved by the Research Ethics Committee of China Medical University. All resected tissue samples were immediately frozen in liquid nitrogen and stored at $-80^{\circ} \mathrm{C}$ until used for analysis. Matching NAT mucosal specimens from at least $5 \mathrm{~cm}$ from the tumor edge were also collected. Hematoxylin-eosin staining of each sample was performed for histopathological evaluation. The histological cancer grade was assessed following guidelines established by the World Health Organization. The depth of wall invasion (pT classification) and the extent of regional lymph node metastasis ( $\mathrm{pN}$ classification) were staged according to the 7 th edition of the tumor-node-metastasis (TNM) staging system $(20,21)$.

Total RNA extraction and reverse transcription (RT). Total RNA was extracted from the gastric cancer tissues and corresponding NATs using TRIzol reagent (Invitrogen Life Technologies, Carlsbad, CA, USA) following the manufacturer's instructions. The concentration and purity of the total RNA were detected by UV spectrophotometry (A260/A280 >1.9) using a NanoPhotometer UV/Vis spectrophotometer (Implen GmbH, Munich, Germany). The total RNA was dissolved in diethyl pyrocarbonate-treated water and reverse transcription (RT) was performed using the Super Script III First-Stand Synthesis System (Invitrogen Life Technologies) for use in polymerase chain reaction (PCR) according to the manufacturer's instructions. In brief, a $10-\mu 1 \mathrm{RT}$ reaction mixture containing $1 \mu \mathrm{g}$ total RNA, $1 \mu 1$ oligo(dT) primer, $1 \mu 110 \mathrm{mM}$ deoxyribonucleotide triphosphate mix and diethylpyrocarbonate-treated water was incubated at $65^{\circ} \mathrm{C}$ for $5 \mathrm{~min}$. Next, a $10-\mu \mathrm{l}$ mixture of $2 \mu \mathrm{l}$ 10X RT buffer, $4 \mu \mathrm{l} 25 \mathrm{mM} \mathrm{MgCl}_{2}, 2 \mu \mathrm{l} 0.1 \mathrm{M}$ dopachrome tautomeras, $1 \mu \mathrm{l}$ RNaseOUT $(40 \mathrm{U} / \mu \mathrm{l})$ and $1 \mu \mathrm{l}$ SuperScript III RT $(200 \mathrm{U} / \mu \mathrm{l})$ was added. Following the addition of $1 \mu \mathrm{l}$ RNase $\mathrm{H}$, the total mixture was incubated in a GeneAmp PCR 9700 Thermocycler (Applied Biosystems Life Technologies, Foster City, CA, USA) for $50 \mathrm{~min}$ at $50^{\circ} \mathrm{C}, 5 \mathrm{~min}$ at $85^{\circ} \mathrm{C}$ and $20 \mathrm{~min}$ at $37^{\circ} \mathrm{C}$. A no-template control was run with the $\mathrm{RT}$ reaction.
Quantitative PCR ( $q P C R)$. Quantitative PCR was performed using the SYBR Premix Ex Taq kit (Takara Biotenchnology, Co., Ltd., Shiga, Japan) on a Light Cycler 480 II Real-Time PCR system (Roche Diagnostics, Basel, Switzerland). Each $25-\mu 1$ PCR reaction mixture contained $2 \mu \mathrm{l}$ of reverse-transcribed product, $12.5 \mu \mathrm{l} \mathrm{SYBR}$ Green mix, $9.5 \mu \mathrm{l}$ RNase-free water, and $0.5 \mu \mathrm{l}$ forward and $0.5 \mu 1$ reverse primers. The reaction was incubated in a 96-well optical plate and amplified in 45 cycles of $95^{\circ} \mathrm{C}$ for $5 \mathrm{sec}, 58^{\circ} \mathrm{C}$ for $30 \mathrm{sec}$ and $72^{\circ} \mathrm{C}$ for $30 \mathrm{sec}$. The primers were designed by Primer Premier software, version 5.0 (Premier Biosoft International, Palo Alto, CA, USA). The primer sequences used were as follows: RP11-119F7.4 forward, 5'-CAGACTTGAAATGGGTGAGATGA-3' and reverse, 5'-TGCCTTTGCTAGTGCAGTGTAT-3'; and glyceraldehyde 3-phosphate dehydrogenase (GAPDH) forward, 5'-CGGATTTGGTCGTATTGGG-3' and reverse, 5'-CTG GAAGATGGTGATGGGATT-3'. GAPDH was used as an endogenous reference to normalize lncRNA expression levels using the $2^{-\Delta \Delta \mathrm{Ct}}$ method, where $\Delta \mathrm{Ct}$ was the difference in threshold cycle $(\mathrm{Ct})$ values. The relative lncRNA expression is presented as the fold-change normalized to the endogenous reference (GAPDH) and relative to the non-tumorous control. Each sample was analyzed in triplicate and repeated three times.

Statistical analysis. RNA expression levels in gastric cancer tissues relative to the control were calculated by the $2^{-\Delta \Delta \mathrm{Ct}}$ formula, where $\Delta \Delta \mathrm{Ct}$ is the difference in the $\Delta \mathrm{Ct}$ values between the treatment tumor cells and the control $\left(\Delta \Delta \mathrm{Ct}=\Delta \mathrm{Ct}_{\text {tumor IncRNA }}-\Delta \mathrm{Ct}_{\mathrm{NAT} \text { IncRNA }}\right)$, and $\Delta \mathrm{Ct}$ is the difference in the $\mathrm{Ct}$ value between the target and endogenous reference (GAPDH; $\Delta \mathrm{Ct}=\mathrm{Ct}_{\text {lncRNA }}-\mathrm{Ct}_{\mathrm{GAPDH}}$ ). If the expression levels of the treatment and control cells were equal, $\Delta \Delta \mathrm{Ct}$ was equal to zero and $2^{-\Delta \Delta \mathrm{CT}}$ was equal to one. The relative expression levels of 1ncRNA RP11-119F7.4 in the gastric cancer tissues were determined using the $\Delta \mathrm{Ct}_{\text {tumor IncRNA }}$ and $\Delta \mathrm{Ct}_{\mathrm{NAT} \text { IncRNA }}$ values. Statistical differences in lncRNA expression levels in cancer tissues relative to the non-tumor control were analyzed using Student's t-test, and correlations between lncRNA expression levels and clinicopathological parameters were analyzed using non-parametric tests: The Mann-Whitney $U$ test between two groups and the Krushal-Wallis test for three or more groups. Survival curves were estimated by the Kaplan-Meier method. The log-rank test was used to estimate the statistical differences between survival curves. A receiver operating characteristic (ROC) curve was established to evaluate the diagnostic value for differentiating between gastric cancer and benign diseases. Statistical analysis was performed using SPSS software, version 8.0 (SPSS, Inc., Chicago, IL, USA) and GraphPad Prism, version 5.0 (GraphPad Software, La Jolla, CA, USA). $\mathrm{P}<0.05$ was considered to indicate a statistically significant difference.

\section{Results}

General characteristics of the subjects. Of the 96 patients (median age, 61 years; range, 26-84 years) with gastric cancer included for analysis, the majority $(n=72,75 \%)$ were male, 73 presented with lymph node metastasis (pN stage, N1-N3) 
Table I. Association between the expression of long non-coding RNA RP11-119F7.4 and the clinicopathological features in 96 patients with gastric cancer.

\begin{tabular}{|c|c|c|c|}
\hline Characteristics & No of patients & Expression level $^{\mathrm{a}}$ & P-value \\
\hline Gender & & & 0.148 \\
\hline Male & 72 & $0.55(0.16-1.03)$ & \\
\hline Female & 24 & $1.11(0.27-2.31)$ & \\
\hline Age, years & & & 0.138 \\
\hline$\leq 60$ & 46 & 0.79 (0.26-1.69) & \\
\hline$>60$ & 50 & $0.55(0.13-1.00)$ & \\
\hline Tumor size, $\mathrm{cm}$ & & & 0.204 \\
\hline$<6$ & 40 & $0.72(0.37-1.59)$ & \\
\hline$\geq 6$ & 56 & $0.43(0.14-1.21)$ & \\
\hline Tumor location & & & 0.865 \\
\hline Upper stomach & 5 & $0.62(0.29-1.21)$ & \\
\hline Middle stomach & 35 & $0.78(0.15-1.70)$ & \\
\hline Lower stomach & 55 & $0.48(0.16-1.11)$ & \\
\hline Entire stomach & 1 & 0.68 & \\
\hline Macroscopic type & & & $0.041^{\mathrm{b}}$ \\
\hline Borrmann I-III & 85 & $0.54(0.15-1.20)$ & \\
\hline Borrmann IV & 11 & $0.90(0.50-4.11)$ & \\
\hline Histological grade & & & 0.197 \\
\hline Good & 21 & $0.54(0.04-0.86)$ & \\
\hline Poor & 75 & $0.72(0.22-1.36)$ & \\
\hline Lauren grade & & & $0.020^{\mathrm{b}}$ \\
\hline Intestinal type & 32 & $0.41(0.04-0.95)$ & \\
\hline Diffuse type & 64 & $0.76(0.27-1.64)$ & \\
\hline pT stage & & & 0.882 \\
\hline $\mathrm{T} 1+\mathrm{T} 2$ & 17 & $0.62(0.21-1.18)$ & \\
\hline $\mathrm{T} 3+\mathrm{T} 4$ & 79 & $0.60(0.16-1.23)$ & \\
\hline pN stage & & & 0.414 \\
\hline N0 & 23 & $0.52(0.16-1.11)$ & \\
\hline N1 & 13 & $0.37(0.07-1.27)$ & \\
\hline N2 & 19 & $0.80(0.42-1.70)$ & \\
\hline N3 & 41 & $0.68(0.20-1.52)$ & \\
\hline pTNM stage & & & 0.678 \\
\hline I & 9 & $0.52(0.13-1.01)$ & \\
\hline II & 25 & $0.42(0.11-1.17)$ & \\
\hline III & 62 & $0.72(0.21-1.69)$ & \\
\hline Invasion into lymphatic vessels & & & 0.062 \\
\hline Negative & 16 & $0.28(0.10-0.84)$ & \\
\hline Positive & 80 & $0.72(0.22-1.47)$ & \\
\hline
\end{tabular}

${ }^{\mathrm{a}}$ Median relative expression (25th-75th percentile). ${ }^{\mathrm{b}} \mathrm{P}<0.05$. TNM, tumor-node-metastasis; $\mathrm{p}$, pathological.

and 92 patients had completed follow-up examinations (Table I). OS time was defined as the time between surgery and mortality, whereas disease-free survival (DFS) time was defined as the time between surgery and cancer-specific mortality.

RP11-119F7.4 expression is downregulated in gastric cancer tissues. As presented in Fig. 1, statistically significant differences were observed in the RP11-119F7.4 expression levels between the 96 paired tumor tissues and matched NATs, as determined by qPCR $(\mathrm{P}<0.001$; Student's t-test). RP11-119F7.4 expression levels in the gastric cancer tissues were reduced compared with those in the corresponding normal tissues. Furthermore, the RP11-119F7.4 expression levels in 64/96 (66.7\%) tumor tissues were downregulated compared with the corresponding NATs. 


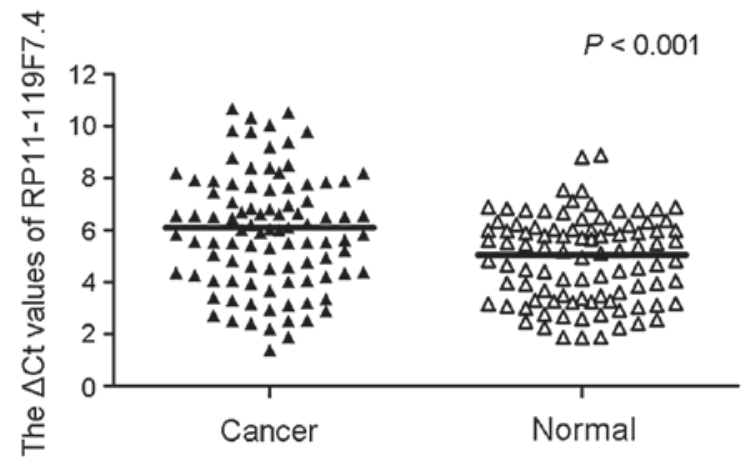

Figure 1. Expression levels of RP11-119F7.4 in gastric cancer tissues and their NATs. RP11-119F7.4 expression was compared in gastric cancer and NAT samples using quantitative polymerase chain reaction $(n=96 ; P<0.001)$. A smaller $\Delta \mathrm{Ct}$ value indicates increased expression. NATs, non-tumor adjacent tissues.

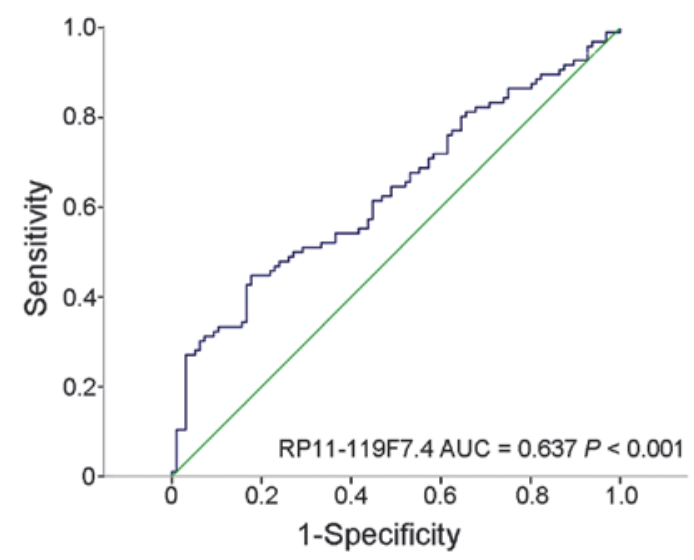

Figure 2. Receiver operating characteristic (ROC) curve of patients with gastric cancer based on RP11-119F7.4 expression in tumor tissues and non-tumor adjacent tissues. AUC, are under the ROC curve.

Diagnostic value of IncRNA RP11-119F7.4 as a biomarker of gastric cancer. The suitability of lncRNA RP11-119F7.4 as a potential biomarker of gastric cancer was evaluated using corresponding NATs as controls to produce an ROC curve. The cut off value was 6.445. The area under the ROC curve was 0.637 (95\% confidence interval, 0.558-0.715; $\mathrm{P}<0.001$ ). The sensitivity and specificity were 0.448 and 0.823 , respectively. The Youden index was 0.271 (Fig. 2). The ROC curve indicated that RP11-119F7.4 has potential diagnostic value in gastric cancer.

Correlations between RP11-119F7.4 levels in cancer tissues and clinicopathological characteristics of patients with gastric cancer. The present study also investigated whether the lncRNA RP11-119F7.4 expression levels were correlated with the clinicopathological characteristics of gender, age, tumor size, macroscopic type and TNM stage in gastric cancer. As shown in Table I, the RP11-119F7.4 levels were associated with macroscopic type $(\mathrm{P}=0.041)$, and the patients with Borrmann type IV gastric cancer tended to have increased RP11-119F7.4 expression levels compared with patients with Borrmann type I-III gastric cancer. Furthermore, it was also observed that the RP11-119F7.4 expression levels of diffuse-type gastric
A

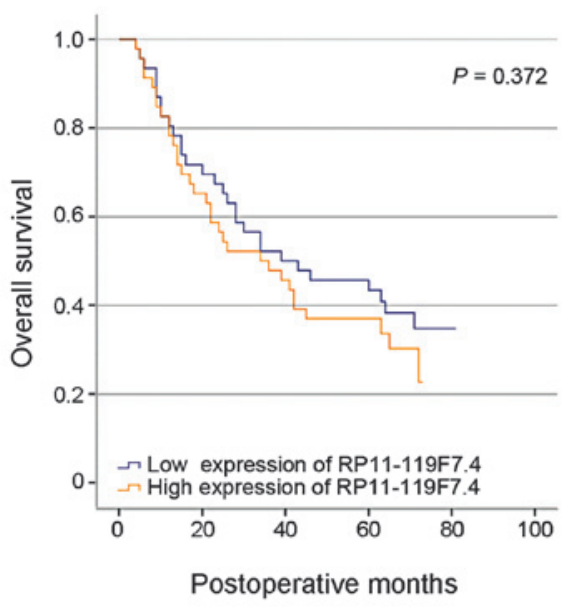

B

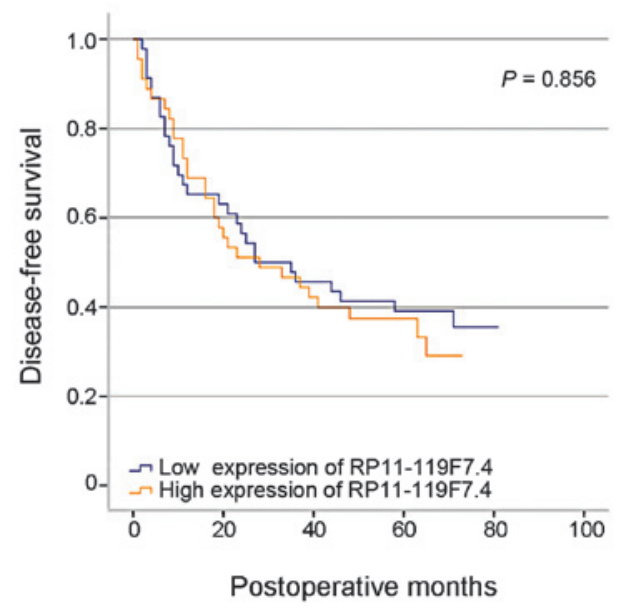

Figure 3. Kaplan-Meier survival curves of patients with gastric cancer based on RP11-119F7.4 expression status. (A) Overall survival of patients in the low and high expression groups. (B) Disease-free survival of patients in the low and high expression groups.

cancer were increased compared with those of intestinal-type gastric cancer $(\mathrm{P}=0.020)$. There were no significant correlations between RP11-119F7.4 expression levels and the clinicopathological characteristics of gender $(\mathrm{P}=0.148)$, age $(\mathrm{P}=0.138)$, tumor size $(\mathrm{P}=0.204)$, tumor location $(\mathrm{P}=0.865)$, histological grade $(\mathrm{P}=0.197)$, $\mathrm{pT}$ stage $(\mathrm{P}=0.882)$, $\mathrm{pN}$ stage $(\mathrm{P}=0.414)$, pTNM stage $(\mathrm{P}=0.678)$ or invasion into the lymphatic vessels $(\mathrm{P}=0.062)$.

Association between RP11-119F7.4 expression and patient survival. Univariate analysis was performed to investigate whether RP11-119F7.4 expression impacted OS and DFS. The RP11-119F7.4 expression levels were determined by qPCR, as aforementioned. Of the 96 included patients, 48 were allocated to the high RP11-119F7.4 expression group, and the remaining 48 to the low RP11-119F7.4 expression group. The median relative expression levels of RP11-119F7.4 were used to determine the cut-off values of the high and low RP11-119F7.4 expression groups in the present study. However, from the results presented in Fig. 3, no significant differences were observed in OS $(\mathrm{P}=0.372)$ and DFS $(\mathrm{P}=0.658)$ between the patients in the high and low RP11-119F7.4 expression groups. 


\section{Discussion}

Tumors associated with gastric cancer are among the most malignant and tend to be asymptomatic in the early stages of disease; thus, they are often not detected late until the disease has progressed to an advanced stage (4). Japan and South Korea provide a government-sponsored screening program for gastric cancer due to the high incidence of this disease in these two countries. However, in these countries, gastric cancer is associated with a low mortality-to-incidence ratio, which may be partly due to the aforementioned population-based screening in regions with a high prevalence of disease (3). Therefore, biomarkers to indicate morbidity associated with gastric cancer are required, particularly for use among populations with a high prevalence of disease. A previous study demonstrated that lncRNAs may function as a novel class of diagnostic and treatment indicators of several types of cancer (8). However, the role of lncRNA expression in gastric cancer remains largely unstudied. In fact, to the best of our knowledge, the present study is the first to investigate the association between RP11-119F7.4 expression and the clinicopathological characteristics and prognosis of gastric cancer based on qPCR data. The results of the present study indicated that lncRNA RP11-119F7.4 was more frequently downregulated in the gastric cancer tissues compared with their matched NATs. Furthermore, the results demonstrated that the RP11-119F7.4 expression levels were associated with macroscopic type and Lauren grade.

Increasing evidence has indicated that IncRNAs participate in a wide variety of physiological and pathological processes by modulating gene expression at the transcriptional, post-transcriptional and epigenetic levels (22-24). At the transcriptional level, a number of lncRNAs regulate gene expression depending on the sequence and relative position, for example, by binding to the promoters of target genes and forming stable DNA-RNA triplex complexes to affect transcription initiation; this process may also inhibit the transcription process of targeted genes and subsequently silence expression (25). At the post-transcriptional level, lncRNAs may competitively bind to target mRNA and block the binding sites of transcription factors, leading to dysregulation of mRNA translation, splicing and degradation (26). lncRNAs regulate gene expression at the epigenetic level through numerous processes, including DNA methylation, histone modification and chromatin remodeling (27).

A number of previous studies have demonstrated that lncRNA dysfunction is closely associated with transcriptional regulation $(12,28,29)$. In addition, other previous studies have reported that ectopic lncRNA expression is associated with tumorigenesis, tumor proliferation, invasion and metastasis $(8,30,31)$. In the present study, differences in the expression levels of 1ncRNA RP11-119F7.4 were observed between the gastric cancer tissues and matched NATs. For patients with gastric cancer, diagnosis and treatment in the early stages of disease may improve their survival time. At present, the most common methods to detect gastric cancer are electronic gastroscopy and histopathological analysis (3). It is therefore necessary to identify novel diagnostic biomarkers of gastric cancer. To this end, ROC curves were used to evaluate the potential diagnostic suitability of RP11-119F7.4 in the present study. The results demonstrated that RP11-119F7.4 had potential diagnostic value in gastric cancer and further indicated that increased expression levels tended to be associated with Borrmann type IV and diffuse-type gastric cancer. A number of previous studies have indicated that Borrmann type IV and diffuse Lauren-type gastric cancers were associated with a worse prognosis compared with other types $(32,33)$. According to the results of the present study, RP11-119F7.4 expression levels may be associated with tumorigenesis and the level of malignancy in gastric cancer. Although statistically significant differences were not observed in the survival analysis, a trend towards a worse prognosis was observed in the patients with relatively increased RP11-119F7.4 expression levels. These findings were supported by the correlation between the clinicopathological characteristics and the RP11-119F7.4 expression levels.

Numerous factors have been observed to downregulate lncRNA expression. Yang et al (34) demonstrated that lncRNA-LET was downregulated in a number of different tumor types and indicated that the reduced expression of lncRNA-LET may be a result of dysregulated histone acetylation. Another previous study by Liu et al (35) indicated that p53 directly interacts with the p53 response element in the upstream region of lncRNA loc285194 and regulates lncRNA expression in colorectal cancer. Competing endogenous RNAs (ceRNAs) are hypothesized to form large-scale regulatory networks and may be important in pathological processes, including cancer development and progression (36). miRNAs are key components of the ceRNA network and may affect the expression of IncRNA in cancer. For example, members of the miR-200 family have been reported to regulate lncRNA-ATB expression in hepatocellular carcinoma (37). As aforementioned, lncRNAs are likely to be regulated by numerous factors, therefore further investigations are required to identify mechanisms that participate in lncRNA RP11-119F7.4 dysregulation in gastric cancer.

In conclusion, the results of the present study demonstrated that lncRNA RP11-119F7.4 expression was downregulated in gastric cancer, which was associated with the macroscopic type and Lauren grade. RP11-119F7.4 is therefore a potential novel biomarker and diagnostic target in gastric cancer. However, the molecular mechanisms that regulate RP11-119F7.4 expression in gastric cancer require further study.

\section{Acknowledgements}

The authors would like to thank the Department of Surgical Oncology of the First Hospital of China Medical University for providing human gastric tissue samples, and the College of China Medical University for providing technical assistance in the experiments. The present study was supported by the National Science Foundation of China (grant nos. 81201888, 81372549 and 81172370), the Specialized Research Fund for the Doctoral Program of Higher Education (grant no. 20122104110009) and the Natural Science Foundation of Liaoning Province (grant no. 2014029201). 


\section{References}

1. Hartgrink HH, Jansen EP, van Grieken NC and van de Velde CJ: Gastric cancer. Lancet 374: 477-490, 2009.

2. Ferlay J, Shin HR, Bray F, Forman D, Mathers C and Parkin DM: Estimates of worldwide burden of cancer in 2008: GLOBOCAN 2008. Int J Cancer 127: 2893-2917, 2010.

3. Shen L, Shan YS, Hu HM, et al: Management of gastric cancer in Asia: resource-stratified guidelines. Lancet Oncol 14: e535-e547, 2013.

4. Thiel A and Ristimaki A: Gastric cancer: basic aspects. Helicobacter 17 (Suppl 1): 26-29, 2012.

5. Yan B and Wang Z: Long noncoding RNA: its physiological and pathological roles. DNA Cell Biol 31 (Suppl 1): 34-41, 2012.

6. Qi P and Du X: The long non-coding RNAs, a new cancer diagnostic and therapeutic gold mine. Mod Pathol 26: 155-165, 2013.

7. Wapinski $\mathrm{O}$ and Chang HY: Long noncoding RNAs and human disease. Trends Cell Biol 21: 354-361, 2011.

8. Qiu MT, Hu JW, Yin R and Xu L: Long noncoding RNA: An emerging paradigm of cancer research. Tumour Biol 34: 613-620, 2013.

9. Maruyama R and Suzuki H: Long noncoding RNA involvement in cancer. BMB Rep 45: 604-611, 2012.

10. Yang Z, Zhou L, Wu LM, et al: Overexpression of long non-coding RNA HOTAIR predicts tumor recurrence in hepatocellular carcinoma patients following liver transplantation. Ann Surg Oncol 18: 1243-1250, 2011.

11. Kim K, Jutooru I, Chadalapaka G, et al: HOTAIR is a negative prognostic factor and exhibits pro-oncogenic activity in pancreatic cancer. Oncogene 32: 1616-1625, 2013.

12. Gupta RA, Shah N, Wang KC, et al: Long non-coding RNA HOTAIR reprograms chromatin state to promote cancer metastasis. Nature 464: 1071-1076, 2010.

13. Kogo R, Shimamura T, Mimori K, Kawahara K, Imoto S, Sudo T, et al: Long noncoding RNA HOTAIR regulates polycomb-dependent chromatin modification and is associated with poor prognosis in colorectal cancers. Cancer Res 71: 6320-6326, 2011.

14. Niinuma T, Suzuki H, Nojima M, et al: Upregulation of miR-196a and HOTAIR drive malignant character in gastrointestinal stromal tumors. Cancer Res 72: 1126-1136, 2012.

15. Tano K, Mizuno R, Okada T, et al: MALAT-1 enhances cell motility of lung adenocarcinoma cells by influencing the expression of motility-related genes. FEBS Lett 584: 4575-4580, 2010.

16. Zhang EB, Kong R, Yin DD, et al: Long noncoding RNA ANRIL indicates a poor prognosis of gastric cancer and promotes tumor growth by epigenetically silencing of miR-99a/miR-449a. Oncotarget 5: 2276-2292, 2014.

17. Bi HS, Yang XY, Yuan JH, et al: H19 inhibits RNA polymerase II-mediated transcription by disrupting the hnRNP U-actin complex. Biochim Biophys Acta 1830: 4899-4906, 2013.

18. Mourtada-Maarabouni M, Pickard MR, Hedge VL, Farzaneh F and Williams GT: GAS5, a non-protein-coding RNA, controls apoptosis and is downregulated in breast cancer. Oncogene 28: 195-208, 2009.
19. Jia LF, Wei SB, Gan YH, et al: Expression, regulation and roles of miR-26a and MEG3 in tongue squamous cell carcinoma. Int J Cancer 135: 2282-2293, 2014.

20. Hamilton SR, Aaltonen LA (Eds): World Health Organization Classification of Tumours. Pathology and genetics of Tumours of the Digestive System. IARC Press, Lyon, Paris, 2000.

21. Sobin L, Gospodarowicz M, Wittekind C (Eds): International Union Against Cancer (UICC). TNM classification of malignant tumours. 7th Edition. Wiley-Liss, NewYork, NY, USA, pp117-126, 2010.

22. Tsai MC, Manor O, Wan Y, et al: Long noncoding RNA as modular scaffold of histone modification complexes. Science 329: 689-693, 2010

23. Gupta RA, Shah N, Wang KC, et al: Long non-coding RNA HOTAIR reprograms chromatin state to promote cancer metastasis. Nature 464: 1071-1076, 2010.

24. Cesana M, Cacchiarelli D, Legnini I, et al: A long noncoding RNA controls muscle differentiation by functioning as a competing endogenous RNA. Cell 147: 358-369, 2011.

25. Martianov I, Ramadass A, Serra Barros A, Chow N and Akoulitchev A: Repression of the human dihydrofolate reductase gene by a non-coding interfering transcript. Nature 445: 666-670, 2007.

26. Gong Z, Zhang S, Zhang W, et al: Long non-coding RNAs in cancer. Sci China Life Sci 55: 1120-1124, 2012

27. Yap KL, Li S, Munoz-Cabello AM, et al: Molecular interplay of the noncoding RNA ANRIL and methylated histone H3 lysine 27 by polycomb CBX7 in transcriptional silencing of INK4a. Mol Cell 38: 662-674, 2010.

28. Hung T and Chang HY: Long noncoding RNA in genome regulation: prospects and mechanisms. RNA Biol 7: 582-585, 2010.

29. Yang L, Lin C, Jin C, et al: lncRNA-dependent mechanisms of androgen-receptor-regulated gene activation programs. Nature 500: 598-602, 2013.

30. Esteller M: Non-coding RNAs in human disease. Nat Rev Genet 12: 861-874, 2011

31. Gibb EA, Vucic EA, Enfield KS, et al: Human cancer long non-coding RNA transcriptomes. PLoS One 6: e25915, 2011.

32. An JY, Kang TH, Choi MG, Noh JH, Sohn TS and Kim S: Borrmann type IV: an independent prognostic factor for survival in gastric cancer. J Gastrointest Surg 12: 1364-1369, 2008.

33. Bravo Neto GP, dos Santos EG, Victer FC and Carvalho CE: Lymph node metastasis in early gastric cancer. Rev Col Bras Cir 41: 11-17, 2014.

34. Yang F, Huo XS, Yuan SX, et al: Repression of the long noncoding RNA-LET by histone deacetylase 3 contributes to hypoxia-mediated metastasis. Mol Cell 49: 1083-1096, 2013.

35. Liu Q, Huang J, Zhou N, et al: LncRNA loc285194 is a p53-regulated tumor suppressor. Nucleic Acids Res 41: 4976-4987, 2013

36. Salmena L, Poliseno L, Tay Y, Kats L and Pandolfi PP: A ceRNA hypothesis: The Rosetta Stone of a hidden RNA language? Cell 146: 353-358, 2011

37. Yuan JH, Yang F, Wang F, et al: A long noncoding RNA activated by TGF-beta promotes the invasion-metastasis cascade in hepatocellular carcinoma. Cancer Cell 25: 666-681, 2014. 